\title{
Protected but vulnerable
}

BOOK TITLE:

Plant invasions in protected areas: Patterns, problems and challenges

\section{BOOK COVER:}

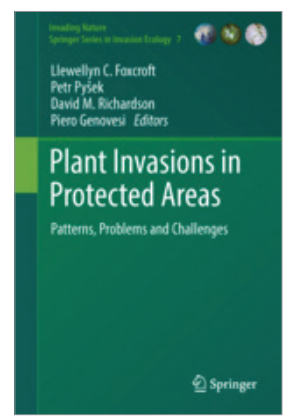

\section{EDITORS:}

Llewellyn C. Foxcroft, Petr Pyšek, David M. Richardson and Piero Genovesi

\section{ISBN:}

9789400777491

\section{PUBLISHER:}

Springer, EUR169.99

(hardcover), EUR142.79 (ebook)

\section{PUBLISHED:}

2013

\section{REVIEW TITLE:}

Protected but vulnerable

\section{REVIEWER:}

Brian W. van Wilgen

\section{EMAIL:}

bvanwilgen@sun.ac.za

\section{AFFILIATION:}

Centre for Invasion Biology, Department of Botany and Zoology, Stellenbosch University, Stellenbosch, South Africa

\section{POSTAL ADDRESS:}

Department of Botany and

Zoology, Stellenbosch University, Matieland 7602, South Africa

\section{HOW TO CITE:}

Van Wilgen BW. Protected but vulnerable. S Afr J Sci. 2014;110(5/6), Art. \#a0062, 1 page. http://dx.doi. org/10.1590/sajs.2014/a0062

(C) 2014. The Authors. Published under a Creative Commons Attribution Licence.
The ongoing transformation of natural ecosystems to provide food, water, fibre, industrial development and space to live for an unprecedented and growing number of people has led to a global environmental crisis. Thousands of species are now threatened with extinction as a direct result of some form of human activity. One of the strategies for preventing a complete transformation of the globe is to set aside protected areas, where species, habitats and ecosystems should be safeguarded from disturbance. However, these protected areas face many challenges, not least of which is invasion by hundreds of newly introduced species that displace the indigenous biota, disrupt ecosystem processes and, in many cases, completely transform the invaded ecosystems. Plant Invasions in Protected Areas provides the first global synthesis of invasive alien species in protected areas since a review conducted 25 years ago under the auspices of the Scientific Committee on Problems of the Environment (SCOPE). ${ }^{1}$

The number of protected areas in the world has grown sevenfold over the past half century, from $\sim 20000$ in 1970 to almost 158000 in 2011, and the network now covers almost 15\% of the earth's land surface. Invasive alien species have been present in these areas for a long time, but their impacts are only now really starting to be felt, and are set to grow. Finding ways of dealing with these problems is fast becoming one of the main headaches for managers of many protected areas worldwide. The book sets out to document the understanding of the problem in the context of modern invasion ecology, and to determine how current understanding can support successful management that will limit further negative impacts. Conservation scientists by and large agree that invasive alien plants in protected areas should and can be brought under control, but carrying out such management can also be a wicked problem. As pointed out in the book, matters are complicated by the fact that some people even welcome the alien species, ${ }^{2}$ or argue that alien invasions should be accepted as inevitable and perhaps even desirable. In addition, some managers of protected areas try to address these problems by attempting to find beneficial uses for alien species, in most cases leading to further conflict, and failure of control efforts.

The book contains a wealth of information on the origins and status of plant invasions, and their management, in protected areas across the world. The majority of impacts associated with invasive alien species have to date been felt on islands. Prior to human settlement (in some cases very recent), islands were protected from invasions by the long distances from sources of alien species. Consequently, islands proved to be very vulnerable to invasion by newly introduced species. The occupation of ocean islands by people led to the extinction of many unique species, initially directly by hunting, but more recently because islands were swamped by alien species, many invasive. For example, about $70 \%$ of the 1000 vascular plant species of the Azores in the North Atlantic are alien. Not surprisingly, therefore, this book has a wealth of information on invasions in protected areas on islands, including those in the Mediterranean, Pacific, Indian, Atlantic, and Southern Oceans. These oceans include iconic World Heritage Sites such as the Galapagos and Aldabra, and the remote islands of the Southern Ocean. There is much to be learnt from islands, and this knowledge is important because severe impacts associated with invasive species, once regarded as island phenomena, are increasingly being felt on continents.

Much of the information is presented in a series of often fascinating case studies, which address the management of both individual species and of areas. African examples include a 'botanical garden' that was established in 1903 in the Amani Nature Reserve, Tanzania (Amani is part of East Usambara, a biodiversity hotspot of global importance). Here over 600 alien woody species were planted in blocks covering 300 ha, leading to the naturalisation of 73 species, 11 of which are now serious invaders. Conservation staff in the Kruger National Park, South Africa, were for a considerable time responsible for the ongoing introduction and cultivation of numerous invasive alien plants in tourist camps and staff villages, despite knowledge of their invasive potential and policies that prevented these practices. Thus, it was often the very people appointed to manage protected areas that set the scene for their degradation through invasion.

Whether or not this problem can be contained is the focus of the final third of the book. Here the options available to managers are thoroughly reviewed, and the need for a comprehensive approach becomes clear to the reader. Such a comprehensive approach should include preventing new introductions, regular surveillance, early detection and rapid response, eradication where possible, biological control, raising awareness, capacity building, political lobbying, integration of control into protected area management plans, management of invasions outside of the protected area boundary, and ecosystem restoration. The clear message that emerges is that managers need something of a paradigm shift away from 'weed management' (an agricultural concept in which the aim is to control certain established weeds), to management for biodiversity outcomes, in which the goal is to protect biodiversity, and which requires a much broader approach, better planning and regular monitoring. Much experience has been gained from the management, across the globe, of the 135 protected areas that are reviewed in this book. This book is one that should not only be read by students of invasion ecology, but also by conservation policymakers and the managers of protected areas. Whether or not they will is another question, as it is well known that a wide gap exists between research-based texts such as this one, and implementation of the recommendations in practice. This vital aspect is addressed only very briefly in the book under the heading 'Bridging the science-management divide', which refers to high-level coordinating bodies. In my view, much closer partnerships between researchers and on-the-ground managers will be needed - a substantial challenge to the research community. The lessons documented in this book deserve to reach a much wider audience than they probably will, and I would recommend this book to anyone involved with the management of biological invasions anywhere in the world.

\section{References}

1. Macdonald IAW, Loope LL, Usher MB, Hamann 0. Wildlife conservation and the invasion of nature reserves by introduced species: A global perspective. In: Drake J, Mooney HA, Di Castri F, editors. Biological invasions: A global perspective. Chichester: Wiley; 1989. p. 215-255.

2. Dickie IA, Bennet BM, Burrows LE, Nuñez MA, Peltzer DA, Porté A, et al. Conflicting values: Ecosystem services and invasive tree management. Biol Invasions. 2014;16:705-719. http://dx.doi.org/10.1007/s10530-013-0609-6 